\title{
Collaborative Innovation to Car Class Professional Service Ability in Regional Industry
}

\author{
Ziyun Li and Hui Wang \\ Wuhan City Vocational College, 430064 \\ 1981921130@qq.com,2228721078@qq.com
}

\begin{abstract}
Keywords: Collaborative innovation; Professional services; Regional industry; Talent training mode; Mechanism
\end{abstract}

\begin{abstract}
To serve the local economy is the main responsibilities in higher vocational colleges; its specialty construction should be adapted to regional industry development. Based on theoretical research and case analysis, to increase the ability of regional industry car class professional service, to create substantive collaborative innovation platform; to build collaborative innovation personnel training mode; to strengthen the construction of curriculum, to create high-quality professional; to multiply subject constructing university-enterprise collaboration, resource integration, value integration, interest integration and coordinated implementation of long-term mechanism.

Speciallized in higher vocational colleges and regional economy development of collaborative innovation combining site, technical skills is important carrier of regional industry personnel training and services. Auto industry is the first pillar industry in the next decade Wuhan, Wuhan to into a world-class car, become the world's largest passenger car production base. Wuhan City Vocational College class professional advantage for regional industry of key construction four characteristic specialty, characteristic specialty is the core competitiveness of vocational education important carrier, only adhere to the "depth fusion with industry, improve power" policy, the resources into the collaborative innovation platform and the superiority of cooperation, to improve the car class professional service and the ability of leading the regional industry development.
\end{abstract}

\section{The Connotation of Collaborative Innovation in Higher Vocational Colleges}

Collaborative innovation is the earliest of the Massachusetts Institute of Technology, Peter becomes. Collaborative innovation refers to the integration and innovation elements in the system of innovation resources flow freely, and changed from disorderly to orderly, value-added knowledge and interests as the core, with industry enterprises, universities and research institutes, governments and education departments for innovation main body of the value creation process [1]. Refers to talent cultivation in higher vocational colleges collaborative innovation, professional construction, professional scientific research innovation ability as the core of the trinity, vigorously promote the industry enterprise, higher vocational colleges, local governments, research institutes, the depth of the fusion set up to satisfy the needs of the industry personnel training and scientific research of collaborative innovation model.

\section{The Propulsion Motor Vehicles Professional Connotation Construction of Basic Direction}

Collaborative innovation is the core of professional connotation construction between colleges. Between collaborative innovation is the key to the standards of industry enterprise of advanced technical standards, post standard and professional deconstruction reconstruction, combined with the enterprise technical experts experience, converted to establish new course content and professional standards, and through professional standard led industry development. Higher vocational education and professional knowledge as well as teachers' personal knowledge involved in the industry and the process of technological innovation, could also provide industrial technology innovation and industry enterprise expert different way of thinking and path. Higher vocational colleges collaborative innovation is to strive for more social resources, attract more capital and projects, develop the school itself and promote industrial upgrading. Collaborative innovation is the 
core of" open, sharing, integration, high efficiency", collaborative innovation is the key to create synergy innovation platform, set up the mechanism of synergy innovation [3].

\section{Case: Automotive Engineering and Collaborative Innovation to Explore Regional Industry Development.}

Through to the automobile specialized practice and research, the author analyzes and sums up the ascension of higher vocational colleges collaborative innovation of service industry development way and the path [4].

Basic Situation. Wuhan city vocational college transformation was established in 2004, from 2004 normal colleges and universities, college was established in 2008 cars, consists of four major and Daimler (Mercedes-Benz) cast star education project (Wuhan) base, changan ford central China training center and other six bases and training center, a car, institute of technical services, set up Wang Hui and zheng-fan li (both chutian skills teacher) two master studio. To set up a batch of collaborative innovation platform and practical results were obtained in production and education: one is 1000 people every year for the social training, social services income is more than 400 ten thousand yuan, research and development of automobile technology service and achieved the international first-class level; The second is for students majoring in automobile five consecutive terms on behalf of the higher vocational and technical colleges in Hubei province to participate in the "comprehensive failure diagnosis and elimination", such as the first prize in group block 11 awards. In 2015, Michael, vocational employment report points out that the Wuhan city, Hubei province vocational college for nearly three years car class students graduate student's income reached 5104 yuan a year later, is the first in Hubei province with graduates. Three is a professional automobile marketing and service become professional vocational education in Hubei province demonstration characteristics, vehicle inspection and maintenance technology become key professional vocational education in Hubei province. At present, the car "school strongest in Wuhan city vocational college" has become the industry consensus, business valuation "talent cultivation to achieve the level of the traditional mode to train hard to achieve". Initially formed the pattern of cooperative innovation of higher vocational education and industrial development, promote the professional service ability.

The Coordinated Development between Higher Vocational Colleges and Professional Training Objectives, Explore Collaborative Education Training Mechanism. In 2012, the Institute of Automotive and Changan Ford Motor Co., LTD., establish collaborative innovation platform, unlike traditional university-enterprise cooperation schools not only cultivate talents for the enterprise, and provides the knowledge and intellectual support for the enterprise, enterprise development for the automotive college technical skill talent training standards, training double team and improve the ability of scientific research, built in 10 million central China automotive training center at the same time, each year to provide ten of the new models for car ford college training all the teachers and students. To develop technical skills training mode innovative automobile talents training target to, develop automotive talent training scheme based on modern vocational education concept and professional teaching standards, with the industry standard and responsibility of cohesion, and translated into the automobile electrical equipment system and the maintenance, the engine electric control principle and the maintenance and so on five core courses; To students a comprehensive sustainable development, cooperative development car etiquette (maintenance, marketing), the art car, car maintenance, car lights) such as the humanities courses.

The implementation path, the enterprise will be introduced to the market project in the construction of professional school. Basf greater China painting training center each year in Hubei sanhuan employees and for the group to undertake coin spray repair the game. Automotive technical service institute, the master studios and Wu Hanze bond technology co., LTD. Participate in the auto parts development and production, such as relay products formed a brand. Bosch automotive diagnostic center campus $34 \mathrm{~s}$ shops and auto fault diagnosis and maintenance. In collaborative innovation platform, the teacher's scientific research and technical personnel and apprentices, students or employees. Industry enterprise standards and post knowledge into the education 
teaching, the education teaching needs and constantly reversed transmission industry innovation enterprise standards. From effect, greatly improve the professional quality and professional skills of the students, and students' loyalty, professional dedication and innovation has been the industry greatly must, enrollment and employment. Car, at the beginning of the school of teacher learning background and work background is normal college, the theory of learning and teaching is a significant characteristic, the lack of the cognition of engineering disciplines, collaborative innovation joint schools and industries, and teachers in substantive platform of seasoning thoroughly remould oneself, professional ability and scientific research ability improved greatly.

The Case Discussion. Car class professional advantage in higher vocational colleges and industry resources, the organic integration of regional industry and higher vocational colleges in talent, technology, curriculum, scientific research efforts, by building collaborative innovation mechanism, structures, higher vocational education and regional industry collaborative innovation platform, the automobile class professional personnel training, product research and development activities to avoid the university-enterprise cooperation in the past caused by lack of substantive platform work cannot be carried out. Unlike traditional university-enterprise cooperation, collaborative innovation platform is the organic integration of school and enterprise, the resources of both sides of the substantive institution. Substantive institution by the joint construction and development, financial, human and other resources in higher vocational colleges and enterprises in their respective advantages. On the function orientation, substantive institutions mainly undertake automobile industry technical skills training, at the same time, according to the demand of enterprises and industry development trend, between the two sides of collaborative innovation development team, for auto product design development. Look from the cost allocation, the enterprise through investment and technical personnel as part-time teachers, provide real learning projects, developing a variety of ways such as double teachers, bear the cost part of talent training. By putting teachers, information resources, the school facilities, a variety of ways, such as land resources, to undertake the cost of part of the enterprise development.

Automotive engineering and collaborative innovation made some achievements, the basis of a collaborative innovation in higher vocational colleges and enterprises cooperation basis, cooperation and cooperation willingness. 2 it is formed in higher vocational colleges with regional industry innovation mechanism and platform. Mechanism includes cooperation, profit distribution, cost allocation, resolving conflicts of each subject in the cooperation. Three is in higher vocational colleges and the regional industry has formed a highly recognition and value sharing, broke through the traditional value conflicts in university-enterprise cooperation pattern and cause unsustainable situation of cooperation.

\section{Increase the Ability of Regional Industry Car Class Professional Service.}

\section{To Create Synergy Innovation Platform for the Substantive. Learning to Collaborative}

Willingness on Both Sides. Build collaborative innovation of substantive platform should follow three basic elements: cooperative intention, common goals, information exchange [5]. Common willingness is the key to decide between collaborative, common goal is to produce common intention of the premise and foundation, information communication is the common aspiration and common contact and exchange of the target, is a dynamic process of collaborative innovation, is the necessary condition to promote substantive platform between colleges. School and enterprise is to establish substantive platform have a common understanding, the collaborative vision through communication, form a cooperative innovation action [6]. Through the example above, the Wuhan city vocational college and changan ford motor co., LTD., have synergy will and common goals, to form a substantive platform.

Both Sides Should Have a Common Interest Between Production Base. Having a common 
interest is the key to form a substantive collaborative innovation platform. For enterprises to obtain sufficient technical skills, high quality talent and continuous technological innovation is the most direct and the most significant benefits. In addition, the enterprises participate in vocational education, the social responsibility of invisible benefits such as social reputation is also important. For vocational colleges, improve the quality of the talents cultivation, education levels and conditions, and the student good jobs, realize the sustainable development of its own [7].

\section{Build Collaborative Innovation Personnel Training Mode.}

Pay Attention to the Construction of Double Type Teachers, to Introduce High Level and High Quality Enterprise Talent Enrolled Part-time Teaching. Master studio is the cultural inheritance, skills teacher, industry leader to take the lead, they have a high level of technical skills and superb skills, have a high professional spirit, and of higher vocational colleges professional construction and personnel training plays an important role in lead and lead, to full time teachers pass, help, belt master effect, promote the teachers' technical skill accumulation and innovation [8].

To Strengthen the Practice Teaching, Improve the Students' Practical Ability. In the practice base, raise teaching or training center to carry out the project teaching, in the real environment in teaching to improve students' practical ability and professional quality. Teaching plans to ensure that the practice teaching with theory teaching time have a certain proportion, the proportion of professional core courses both shall not be less than 1 [9], the proportion of professional foundation courses both to slightly lower.

Enhancing University-enterprise between Technical Development and Innovation. Double through many years of professional practice, teachers must have technical skill accumulation and innovation, formed the certain scientific research and development ability, active in science and technology in the collaborative innovation substantive services, to undertake research projects, at the same time, lead the students to set up research and development team, improve the students' scientific research consciousness and level.

\section{To Strengthen the Construction of Curriculum, Create High-quality Professional}

Course of professional, professional training target is the foundation and basis of curriculum system construction. Curriculum system to highlight the core curriculum, a core course is to reflect the characteristics of professional, 2 it is to train the students' ability to obtain a certain jobs [10]. In substantive collaborative innovation platform, the teacher, enterprise technical personnel and master the common development of curriculum system, especially the specialized core curriculum, embarks from the professional post build specialized core curriculum, to the talent training standards and professional teaching standard industry enterprise cohesion and responsibility, under the framework of the target of profession fostering core curriculum.[11].

\section{Acknowledgement}

Social Science Association in Hubei Province in 2016 "social science research funding" project "of higher vocational education and regional industry development of collaborative innovation research" (Wu Social Science Association Article [2016] No.5) of achievements; Wuhan city vocational college field project "of higher vocational education and the regional industry development collaborative innovation research - in automotive technical skills training, for example" (project number: JY2016031) achievements.

\section{References}

[1] Chenjing The collaborative Innovation [M]. Hangzhou: zhejiang university press, 2012, 9-10

[2] Zhou Jin-song. Collaborative innovation promotes characteristic professional service ability [J]. Journal of China university of science and technology, 2013 (8), 65-66 
[3] Lijianqiu QingZhongQuan. Collaborative innovation and higher vocational education development [J]. Journal of higher engineering education research, 2013 (5), 118-121

[4] Long Yan, LouXiaoChun, ying-jie qiu. Promote higher vocational professional services like car industry development ability of empirical study [J]. Journal of vocational and technical education in China, 2013 (28), 85-88

[5] Xu Guozhi. System science [M]. Shanghai: Shanghai science and technology education publishing house, 2000

[6] Tang Zhibin Shi Weiping. Theory of higher vocational education and industrial development logic of collaborative innovation and mechanism [J]. Journal of education and economy, 2015 (4), 3 to 7

[7] Zhou Ling-ling Wang Beibei. Improve the ability of higher vocational colleges, the professional services industry research and exploration [J]. Journal of education teaching BBS, 2014 (11), 248-249

[8] Cong yunfei. Accumulation of technical skills in our vocational colleges and the construction of innovation system [J]. Journal of north China water conservancy and hydropower university (social science edition), 2015 (5) : 89-92

[9] $\mathrm{Xu}$ Bing. The university personnel training mode of collaborative innovation under study to explore the [J]. China's adult education, 2015 (24), 42-43

[10]JiangDayuan. New vocational education research [M]. Beijing: education science press, 2007123

[11]Hou Weizhi Dong Zhaowei, yan-qing liang. Thinking about and course in the major of higher vocational education [J]. Journal of vocational and technical education in China, 2008 (4), 23 to 25 